Le Maguer L, Derégnaucourt S, Geberzahn N. Female preference for artificial song dialects in the zebra finch (Taeniopygia guttata). Ethology. 2021;00:1- 13.

\title{
Authors' pre-print
}

\section{Editor's version available at the following:}

https://doi.org/10.1111/eth.13159 
Female preference for artificial song dialects in the zebra finch (Taeniopygia guttata)

\section{Lucille Le Maguer ${ }^{1,2}$, Sébastien Derégnaucourt ${ }^{1,2,3, *} \&$ Nicole Geberzahnn ${ }^{1,2, *}$}

${ }^{1}$ Laboratoire Éthologie Cognition Développement, Université Paris Nanterre, 200 Avenue de la République, F92001 Nanterre Cedex, France

${ }^{2}$ Université Paris Lumières, 140 rue du Chevaleret, 75013 Paris, France

${ }^{3}$ Institut Universitaire de France, 75005 Paris, France

$\underline{\text { Author's note }}$

* Joint authors.

Correspondence: lucille.lemaguer@gmail.com 
in several songbird species. There is evidence that such dialects contribute to reproductive

4 isolation through variation in female preference. In the wild, there is no report of consistent

5 dialects in populations of zebra finches. However, under laboratory conditions, we were able

6 to artificially create different colony-wide song dialects. In this species, song plays a crucial

7 role in mate choice and the importance of both subadult and adult song experience in shaping

8 song preferences has been well documented. Therefore, we expected females to prefer songs

9 corresponding to their colony's dialect. We measured this preference using an operant test:

10 females could either trigger a song corresponding to their Colony Song Type (CST) sang by an

11 unfamiliar individual, or another conspecific song, corresponding to a Non-Colony Song Type

12 (N-CST). Most females preferred the CST over the N-CST, supporting the idea that zebra finch

13 females exhibit a preference for songs similar to their colony's song. It also reveals that song

14 dialects matter to female zebra finches. It has been proposed that song could be used as an

15 affiliative signal in highly social species. Therefore, preferring the colony dialect could be the

16 consequence of a sexual preference, but also of a social preference. We discuss the potential

17 role of song dialects in the context of social learning.

18 Keywords: female choice, birdsong, operant test, geographical variations, sexual 19 preference, social preference 


\section{Introduction}

Geographical variation in phenotypic traits can have a central role in speciation processes, in particular if such traits play a role in mate choice (Edwards, Kingan, Calkins, Balakrishnan, Jennings, Swanson, \& Sorenson, 2005; Miller, 1956). Birdsong is an example of such a trait as in many songbird species, geographical song variations have been reported, and mate attraction and stimulation is one of its main functions (Catchpole \& Slater, 2008; Kroodsma, 2004; Podos \& Warren, 2007). In such species, males of a same geographical location sing the same song type or share a substantial part of their song repertoire whereas males of different locations vary in their songs (Marler \& Tamura, 1962; Podos \& Warren, 2007). Such vocal geographical variations can lead to song dialects and can be maintained over very long periods of time (Derryberry, 2007; García, Arrieta, Kopuchian, \& Tubaro, 2015; Harbison, Nelson, \& Hahn, 1999; Marler \& Tamura, 1962; Trainer, 1983). Several hypotheses about the functions of dialects have been proposed (Catchpole \& Slater, 2008). According to the "genetic adaptation hypothesis", geographical variation of birdsong allows individuals to recognize and mate with individuals of the same population, promoting the maintenance and development of local adaptations (MacDougall-Shackleton \& MacDougall-Shackleton, 2001; Marler \& Tamura, 1962, 1964; Nottebohm, 1969, 1972). Geographical variation in song could thus influence female mating preferences (Catchpole \& Slater, 2008; Searcy \& Yasukawa, 1996), with females preferring males singing their natal or local song dialect (King, West, \& Eastzer, 1980; MacDougall-Shackleton, MacDougall-Shackleton, \& Hahn, 2001; O’Loghlen \& Rothstein, 1995; Searcy \& Andersson, 1986). According to the "social adaptation hypothesis", song dialects affect social and sexual interactions, but dialectal populations should not be genetically isolated from each other (Payne, 1981). Some studies show indeed a positive correlation between vocal sharing and the maintenance of a territory and/or the reproductive success (Beecher, Campbell, \& Nordby, 2000; Payne, 1982, 1983). Song dialects may also play 
an important role in group cohesion as they may signal group identity (Briefer, Aubin, Lehongre, \& Rybak, 2008; Hausberger, Bigot, \& Clergeau, 2008). It has been shown that song could increase social cohesion in highly social species, such as the European starling (Sturnus vulgaris; Hausberger et al., 2008).

Singing behaviour is often sexually dimorphic, as many sexually selected traits (Catchpole \& Slater, 2008, but see Odom, Hall, Riebel, Omland, \& Langmore, 2014). This is the case in the zebra finch (Taeniopygia guttata), a highly social species in which only males sing. Young zebra finches learn their song by listening, memorising and reproducing the song of conspecifics, mainly adults (Derégnaucourt, 2011 but see Derégnaucourt \& Gahr, 2013). Song learning takes place during a sensitive period of the early life, between 25- and 90-days post-hatch (dph), and past these 90 days, vocal changes are rarely observed (Immelmann, 1969). In the zebra finch, song plays a crucial role in mate choice and the link between song and female preference is well studied (for a review, see Riebel, 2009). Under natural conditions, each male zebra finch has a unique song, which constitutes an individual signature (Clayton, 1988; Cynx \& Nottebohm, 1992) and is recognized by his sexual partner (Clayton, 1988). Female zebra finches also have a sensitive phase for song preference learning (Riebel, 2003) and the importance of subadult song experience in shaping adult song preferences has been well demonstrated: if deprived of adult song during the sensitive phase of their early life, females fail to discriminate differences in song quality and do not show consistent preferences as adults (Lauay, Gerlach, Adkins-Regan, \& DeVoogd, 2004; Riebel, 2000). Females, when adult, do prefer the song they heard when they were young over other songs (Clayton, 1988, 1990; Miller, 1979a, 1979b; Riebel, 2009). In the wild, female mate choice is based on different signal modalities, but it has been demonstrated that the song could potentially provide sufficient information about a male for females to assess his quality and allow them to make their choice (Holveck \& Riebel, 2007). However, within a same population, females can differ in their 
preferences. For example, differences between direct benefits (such as parental care or access to resources) and indirect benefits (inheritance of genes for viability), can lead to differences in female preference (Candolin, 2003). In addition, female preferences can be influenced by social factors such as male/male and female/female competition (Jennions \& Petrie, 1997; Widemo \& Saether, 1999). It has also been suggested that zebra finch females might rank male signals differently in preference tests, or that no single trait might signal the absolute quality of a male (Holveck \& Riebel, 2007).

Until now, studies focusing on zebra finches suggested that dialects could not emerge in this species. Only weak geographical song variations have been found in different Australian populations (Zann, 1993) and it has been concluded that dispersal to and from colonies prevented the formation of colony-specific versions of the song (Zann, 1993). In domesticated populations of zebra finches, a high rate of learning errors probably prevents the establishment of song dialects (Lachlan, van Heijningen, ter Haar, \& ten Cate, 2016). However, in our laboratory, we succeeded to create artificial song dialects. We did so by training male founders of three different colonies to produce a very good imitation of a song model (Le Maguer, Geberzahn, Nagle \& Derégnaucourt, under review). Male offspring raised in these colonies developed songs with a high conformity to the song model, and each song model led to a different dialect (Derégnaucourt, Nagle, Gahr, Aubin, \& Geberzahn, 2014; Le Maguer et al., under review). Female offspring raised in those colonies heard different versions of a unique song type during their early life: the song dialect of their colony. These conditions allowed us to test for a link between song dialects and female preference in a widely studied species. Given that female zebra finches prefer songs they heard when they were young, we predicted that in each colony, females would prefer songs that resemble those produced by males of their colony.

To verify this prediction, we tested female zebra finches with an operant conditioning paradigm (Riebel, 2000; Riebel \& Slater, 1998; Riebel, Smallegange, Terpstra, \& Bolhuis, 

model B (Figure 1a).

\section{Materials and Methods}

2002; Salvin, Derégnaucourt, Leboucher, \& Amy, 2018). During the test, a female had the choice between two response keys, each triggering a different song type when pecked: one response key triggered the playback of the song type of her colony, which we refer to as the "Colony Song Type" (CST), and the other response key triggered the playback of a conspecific song type that was different from the song type of her colony, which we refer to as the "NonColony Song Type" (N-CST). According to our hypothesis, we expected that females would peck more often on the response key triggering the CST than on the key triggering the N-CST.

Subjects and rearing conditions

All subjects in this experiment were adult female zebra finches that hatched and were raised in our laboratory. Subjects originated from three different colonies, each of them founded by males previously trained to produce the same song model (Le Maguer et al., under review). Two colonies (colony A1 and colony A2) were founded by males singing song model A (Figure 1a). The third colony (colony B) was founded by males singing a different song model, song

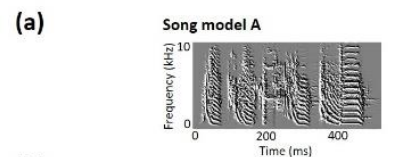

(b) Colony Song Type (CST) for colony A1 females
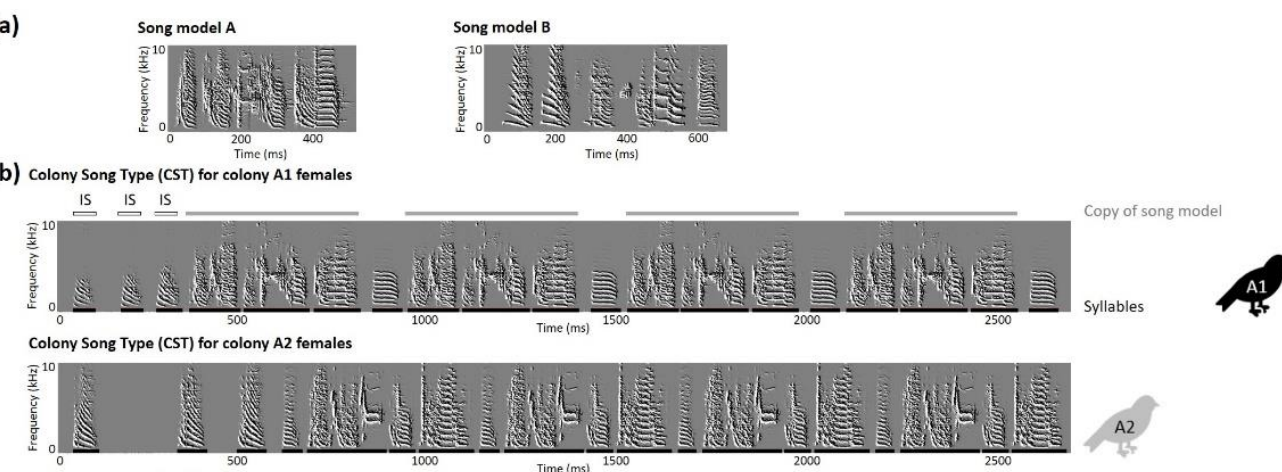

Colony Song Type (CST) for colony B females

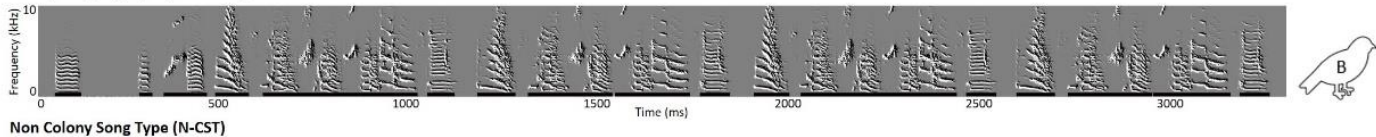

110
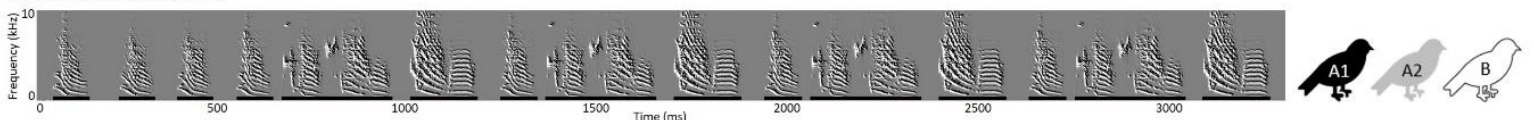
111 Figure 1. Spectrograms illustrating song models of colonies and of songs used as stimuli for 112 the preference test. (a) Spectrograms of song model A and B that had been used to artificially create song dialects. Song model A and B consisted of a single motif each. (b) Example of one set of song stimuli (set \#3) used in the female preference test of the present study. A set was composed of four different song stimuli. Each stimulus consisted of a bout in which the motif was repeated four times. Note that each female subject was exposed to only two out of four song stimuli of a given set: one Non-Colony Song Type (N-CST) and one Colony Song Type (CST), whereby both stimuli were produced by a male unfamiliar to her. Females from different colonies that were tested with the same set of song stimuli were exposed to a different CST stimulus according to their colony. In the first spectrogram (CST for colony A1 females), the different units of a typical zebra finch song are indicated. Introductory syllables (IS) are overlined in white. Syllables are underlined in black. Copies of the song model are overlined in grey. Bird silhouettes to the right of the spectrograms illustrate the females for whom such song stimuli were used: black silhouettes represent song stimuli for a colony A1 female, grey silhouettes represent song stimuli for a colony A2 female and white silhouettes represent song stimuli for a colony B female.

The number of colonies and choice of song models are inherent to the protocol of a previous study focusing on cultural evolution of birdsong (Le Maguer et al., under review). Briefly, after creating colony A1, we created a second colony using the same song model (song model A) but a smaller number of founders in order to test whether the number of founder males

131 has an influence on the findings. We created the third colony using founder males singing a

132 different song model in order to test whether results obtained for song model A could be generalised to another song type.

Details of how we set up colonies have been described elsewhere (Le Maguer et al. under review). Briefly, founder males and founder females of each colony were housed together

136 in a communal aviary containing nest boxes and nesting material, so that they could reproduce 137 freely until we obtained at least 34 male pupils per colony. In colony A1, we obtained a total of 13848 male and 27 female offspring after 346 days. In colony A2 we obtained 34 male and 26 
139 female offspring after 399 days. In colony B we obtained 35 male and 37 female offspring after

140555 days. Birds were individually marked with three coloured rings one of which was always

141 red and numbered. All birds that hatched in those three colonies (including females used for

142 this study) could interact freely with all the other birds of their colony. The three colonies were

143 kept in three different aviaries (3.18 x $3.32 \times 2.84 \mathrm{~m})$, visually and acoustically isolated from

144 each other so that the birds could not hear other songs than those produced by the males of their 145 own colony. All aviaries were set to a 14:10 light:dark (LD) schedule (lights on at 8 am - off at

$14610 \mathrm{pm}$ ) and maintained between 20 and $23^{\circ} \mathrm{C}$. Birds had ad libitum access to water, seeds mix

147 and egg food for exotic finches, as well as sand and cuttlebones. The basic diet was

148 supplemented once a week with vegetables and fruits, and once a month with hard-boiled eggs.

We tested a total of 63 females: 11 from colony A1, 21 from colony A2 and 31 from

colony B. Females from colony A1 were tested at the age of $1601 \pm 86$ days post-hatch (dph), females of colony A2 at $792 \pm 106$ dph and females of colony B at $655 \pm 89 \mathrm{dph}$.

152

\section{Apparatus}

We tested the preference of females for the dialect of their colony by using an operant task with song as a reward (Riebel, 2000; Riebel \& Slater, 1998; Riebel et al., 2002; Salvin et al., 2018). The experimental set-up has been inspired by the one described in Houx \& ten Cate (1999) and used in other studies (Riebel, 2000; Riebel et al., 2002; Salvin et al., 2018). The apparatus consisted of a sound-proof chamber $(85 \times 65 \times 60 \mathrm{~cm})$ containing a metal cage $(46 \mathrm{x}$ $22 \times 26 \mathrm{~cm})$ with two perches separated by $36 \mathrm{~cm}$. A red response key $(1 \mathrm{~cm}$ in diameter) was placed above each perch. Behind each key, a mirror of $10 \mathrm{~cm}$ diameter was placed to reduce the impact of social isolation. Seeds, egg food, water and sand were available ad libitum throughout the experiment. When pecked, each red key triggered the playback of a song, broadcasted via a loudspeaker (Yamaha MS101 III, Frequency Response: $30 \mathrm{~Hz}-20 \mathrm{kHz}$ ) located in between the two response keys. Songs were broadcast at a maximum amplitude of 
$16470 \mathrm{~dB}$ at $30 \mathrm{~cm}$ from the speaker (Roline R0-1350 sound-level meter; fast response $\mathrm{F}$ and low

165 range LO, A settings). This level is comparable to that produced by a singing male (Houx \& 166 ten Cate, 1999). Each sound-proof chamber was equipped with fans providing a low airflow 167 and OSRAM DULUX lights on an automatic 14:10 LD schedule.

168 After manually assigning one specific song to a particular key in SAP 2011 (Sound 169 Analysis Pro software; Tchernichovski, Lints, Derégnaucourt, Cimenser, \& Mitra, 2004), this 170 software controlled the playback and automatically switched songs between the two keys each

171 night, to control for possible side preferences. The software kept track of all key pecks (number 172 of pecks and identity of the key pecked) and stored this information in My SQL Workbench 6.3

173 CE tables, from which we could extract excel files. This allowed us to track females' progress 174 day by day. Response keys were connected to the computer using a National Instruments USB1756501 port. In order to check whether females intentionally pecked the keys during the test, each 176 sound-proof chamber was equipped with a Logitech C920 webcam. For a representation of the 177 experimental set-up, see Figure 2a. 
(a)

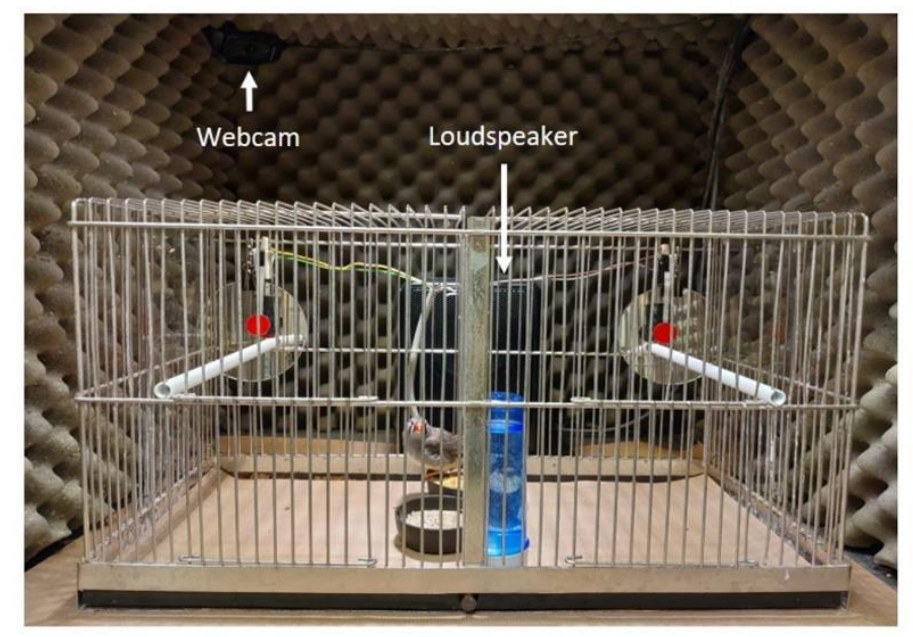

(b)

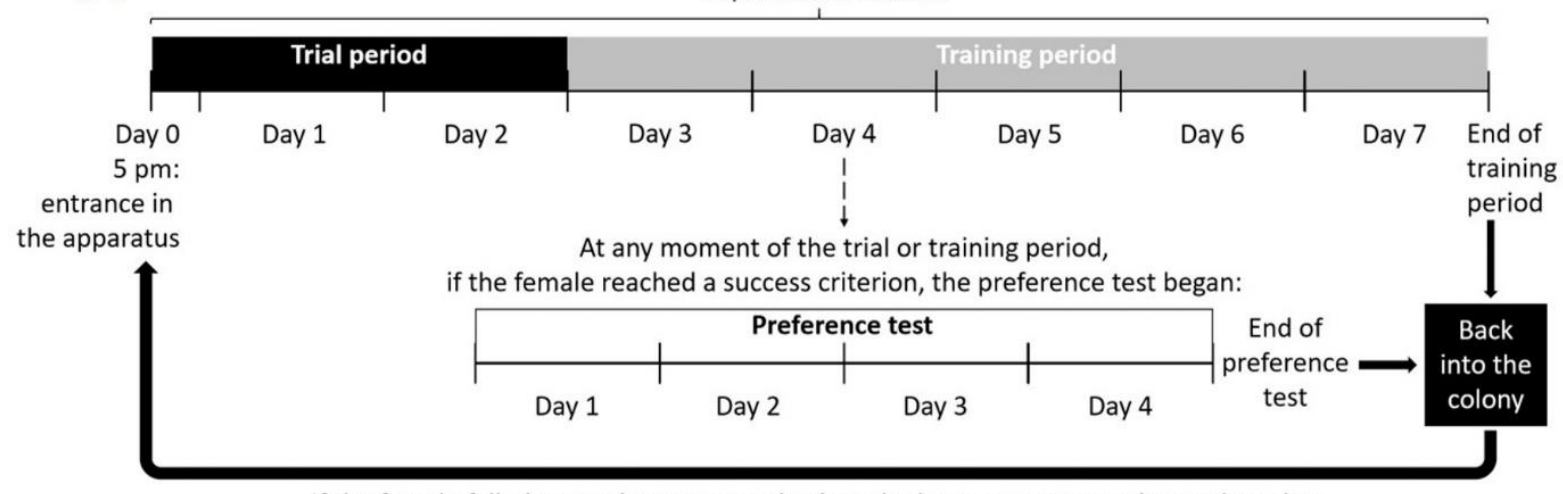

If the female failed to reach a success criterion, she began a new experimental session

(maximum 4 experimental sessions: the last one without training)

179 Figure 2. Experimental apparatus and timeline. (a) Experimental set-up for the preference test.

180 (b) Experimental timeline. Females were housed with members of their colonies until being

181 transferred to soundproof chambers for the experimental session.

Stimuli

It has been demonstrated that female zebra finches are able to generalise their learnt

184 preference for a specific song type (usually the father's song) to the songs of other unfamiliar

185 males (Clayton, 1990; but see Riebel \& Smallegange, 2003). Therefore, and in order to prevent

186 an effect of familiarity in our experiment, both song types used as stimuli (CST and N-CST)

187 were produced by unfamiliar birds. In a previous study we had conducted a detailed song

188 analysis that revealed high similarities between males of colony A1 and colony A2 in song

189 features such as syllable and element repertoire, song variability, inter-syllabic gap distribution 
and song bout structure. At the same time, males from the colonies A1 and A2 differed from those of colony B with respect to these song features (Le Maguer et al., under review). Thus, we had created two different dialects: males from colony A1 and A2 sung one and the same song dialect, males of colony B sung another dialect. The CST for A1 females were songs

194 produced by males of colony A2 and vice versa. Given the large number of males in these

195 colonies, a large pool of songs was available to create the song stimuli. In contrast, no such

196 second colony was available for females of colony B. Therefore, the CST for females of colony

197 B were songs of different males that had been trained to produce an imitation of the song model

198 B but that were not used as founder males for this colony. N-CST for females of the three

199 colonies were sung by males originating from the Max Planck Institute for Ornithology in 200 Seewiesen (Germany). Spectrographic illustrations of different stimuli that were used as a N201 CST are presented in Figure S1.

\section{Song recordings}

We used recordings of undirected songs produced by males when alone in the cage as

204 it is easier to get high-quality recordings of undirected songs than of directed songs. Recordings of directed songs are often polluted by cage noises due to courtship displays of males and calls produced by females. Preference for undirected songs produced by different males have already been shown in female zebra finches (e.g. Holveck \& Riebel, 2007; Riebel et al., 2002). Recordings were made in sound-proof chambers with Behringer C-2 microphones and a PreSonus AudioBox (24 bit/96K) recording interface. Before subsequent processing, we applied a high pass filter at $420 \mathrm{~Hz}$ and set the peak amplitude to $90 \%$ to all the sound files of each male, using Goldwave software (v6.36).

\section{Selection of songs based on the song model}

Zebra finch song is produced in bouts: each song bout usually starts by introductory 214 syllables, followed by one or several renditions of the motif (Figure 1b). Syllables are 
vocalisations that are separated from each other by silent gaps, and the motif is defined as a

216 short and stereotyped sequence of syllables (Figure 1b). To select song stimuli that best represented the colony's song type, we chose songs from males that produced a very good copy of the song model. To do so, we quantified a similarity score between the copy of the male and the song model of his colony, using the song similarity procedure of SAP 2011 (Tchernichovski et al., 2000; Le Maguer et al., under review). Males whose songs were chosen as CST stimuli 221 had a high similarity to the song model (mean $\pm \mathrm{SD}=87 \pm 8$ ).

\section{Creation of song stimuli}

We first selected several song files per male which had a song that could serve as a CST or a N-CST in one of the three colonies. Then, for each male, we selected one natural song bout and digitally modified it using Avisoft SASLab Pro. The aim was to obtain song stimuli that were of similar duration and to mimic the high acoustic stereotypy of natural directed songs (Sossinka \& Böhner, 1980). Thus, in the song bout of each male, we kept the three last introductory syllables (preceding the first motif), followed by four renditions of the motif. Depending on the male, we kept either the first song motif that was then copied three times, or 230 the first two song motifs that were then copied once. We kept the natural gap durations between 231 song motifs. To standardize all song stimuli, amplitude was root-mean square equalised with 232 Praat software (peak digitally scaled to 0.99 ).

To minimise pseudoreplication, we created 10 unique sets of song stimuli, each set being 234 composed of four songs produced by four different males: 1) one male producing a N-CST 235 (conspecific song), 2) one male producing a CST for colony A1 females, 3) one male producing 236 a CST for colony A2 females, 4) one male producing a CST for colony B females (Figure 1b). 237 Note that out of those four stimuli, each female was exposed to only two stimuli during the 238 operant test (one CST and one N-CST). Among the $\mathbf{1 0}$ sets, only seven contained a CST for 239 females of colony B, as we did not have more unfamiliar males singing a good copy of the song 
model B. Therefore, in colony A1 and A2, we assigned one out of 10 sets to each female, whereas in colony B, we assigned one out of seven sets to each female. The same N-CST was broadcasted to females from different colonies who were assigned the same set. However, the CST depended on the colony of the female and was thus different for females from different colonies (Table S1). Within one set, we matched song duration as much as possible (Table S1).

The mean duration of songs $( \pm$ SD) was: $\mathrm{N}-\mathrm{CST}$ songs $=4.09 \pm 1.10 \mathrm{~s}$; CST songs for females of colony A1 $=3.75 \pm 0.99 \mathrm{~s} ;$ CST songs for females of colony A2 $=3.73 \pm 1.14 \mathrm{~s}$; CST songs for females of colony $\mathrm{B}=3.37 \pm 0.47 \mathrm{~s}$. Within each colony, several females were tested with 248 the same set (Table S2).

Preference test

Each female subject was taken from her colony and transferred to the apparatus at around $5 \mathrm{pm}$ (day 0 of the experiment). From this moment on, the female had access to two response keys and could hear the two different song types (N-CST and CST) sung by two unfamiliar males, each one being triggered by one of the response keys. The females had permanent access to the keys, but pecking the keys elicited songs only during the day: from 8 am when the lights switched on, to $10 \mathrm{pm}$ when the lights switched off. As females had to learn how to peck the keys, the first experimental session started with a trial period of two days (day

2571 and day 2 of the experiment). A female could learn to peck the keys by autoshaping after she accidentally pecked a key. We considered that a female had learned the task if we detected at 259 least 10 pecks on each key in one day (first learning criterion). The day on which this success 260 criterion was reached was considered day 1 of the preference test. Following day 1 of the 261 preference test, females had access to the keys during the three following days (day 2, 3 and 4 262 of the preference test), before transferring her back to her colony. Thus, the preference test 263 lasted four full days and assignment of stimuli to response keys was reversed each night, in 264 order to control for side preferences: on two days the CST was triggered by the right key, and 
on two days the CST was triggered by the left key. Females that had not started to regularly peck the keys at the end of the trial period (morning of day 3 of the experiment) underwent a training procedure.

The training period lasted a maximum of five days (from day 3 to day 7 of the experimental session) and consisted of two daily reinforcement sessions. Reinforcement was provided by 1) drawing the attention of the female to the keys by manually pushing each key several times when she was watching, and 2) sticking seeds or nesting material to the response keys to enhance the appeal of the keys. We kept track of the pecks realised by females after each reinforcement session. If a female still had not started to regularly peck the keys at the end of the five-days training period (day 7 of the experiment), she was transferred back to her colony where she rested for at least a week before a second identical experimental session started. Some females exhibited a side preference that could not be overturned by temporarily hiding the preferred key (i.e. the key on which they pecked more often) and reinforcing the nonpreferred key during the training period. We assumed that with the preferred key covered, females would start to peck the non-preferred key and would continue to do so even after uncovering the previously preferred key. However, this was not the case. In Figure S2, we present a comparison of song preferences to side preferences at the colony level. For females exhibiting a side preference, we considered that they learned how to peck a key if they pecked the preferred key at least 20 times a day (second learning criterion). If a female failed to reach one of the two learning criteria during the second experimental session, she underwent a third experimental session after having spent at least a week in her colony.

If during one of the training sessions, the female started to regularly peck on both, or on one particular key, training was stopped. The day that the female reached one of the two learning criteria without any reinforcement was considered day 1 of her preference test. From day 1 on, the test continued until day 4 . Some females did not learn to press the keys during the 
first three experimental sessions. Those females were transferred to the apparatus for a fourth 291 experimental session, this time without any training. If a female still had not reached one of the two learning criteria at the end of this fourth experimental session, we considered that she failed

293 the experiment. The procedure of the whole experiment is presented in Figure $2 \mathrm{~b}$. At any 294 moment of the experiment, we could check whether a female pecked the keys on purpose using 295 webcams that were running continuously during the day.

296 Notes on animal studies

All procedures reported here followed the European regulations on animal experimentation and were approved by the French Ministry for National Education, Higher 299 Education and Research (authorization no. 02609.02). The following statements on sampling biases are made with reference to the STRANGE 301 framework (Webster \& Rutz, 2020). Social background: all females were raised in free range 302 aviaries in which they could interact freely with all members of their colony (males and 303 females) throughout their lives; Trappability and self-selection: all the females within the three 304 colonies were tested, removing any possible bias due to trappability and self-selection; Rearing 305 history: all tested females came from colonies that were created and reared in the same way, 306 with access to the same resources and enrichment (see "Subjects and rearing conditions" section 307 above); Acclimatation and habituation: details concerning acclimatation and habituation to the 308 experimental set-up have been described above in the "Preference test" section; Natural changes 309 in responsiveness: potential changes in females' responsiveness in our experiment could be 310 related to differences in their reproductive state. As zebra finches are considered opportunistic 311 breeders and lack seasonality in breeding (Immelmann, 1968; Zann, 1996), we could not assess 312 females' sexual receptivity before testing; Genetic make-up: all birds came from the same 313 genetic background, as mentioned in the "Subject and rearing conditions" section; Experience: 314 all females of this study had already been captured, handled and tested in sound-proof chambers 
in other experiments previous to this study. As mentioned in the "Preference test" section, a training procedure has been done to adjust the experimental protocol to suit non- or slowlyengaging individuals. According to our above statements, we estimate the STRANGEness of our sample as low. All potential biases related to STRANGE framework that could be due to females' experiences are discussed in the "Discussion" section.

Analysis

Females used several techniques to press the keys, such as pecking it with the beak, pushing it with the feet or the wing, jumping on it or pushing the key by quickly turning around when being close to it. For the sake of simplicity, we refer to all these techniques as "pecking" throughout the article. Due to webcam issues, for three females (one in colony A1 and two in colony B), we had no video confirmation of their pecking success. However, those females had pecked both keys a significant number of times, which led us to believe that those pecks were intentional.

To analyse the females' preferences, we calculated their preference ratio for the CST: total number of pecks for the CST during the four days of test, divided by the grand total of pecks over the four days period. We also calculated preference strength as the number of pecks for the preferred song type, divided by the number of pecks for the less preferred song type.

Statistical analysis

334 we performed one binomial test per female (function binom.test in R), in order to test whether 335 the preference ratio for the CST significantly differed from 0.5 (chance level). We controlled 336 for multiple testing by correcting all 37 individual $p$-values with the p.adjust function in $\mathrm{R}$, 337 using the false discovery rate correction (Benjamini \& Hochberg, 1995). To investigate whether 338 there was a significant preference for the CST at the colony level in each colony, we checked 
whether the mean preference ratio was greater than chance by comparing it to 0.5 using a one-

340 sample t-test. We corrected p-values for multiplicity using the false discovery rate correction.

341 To check whether a link existed between motivation and preference strength, we used

342 Spearman's correlations because data were not normally distributed.

Finally, we tested whether the behavioural responses during the preference test differed

344 between the three colonies to check whether there was a higher preference ratio for the CST or

345 a higher number of pecks during the test in one of the three colonies. We ran two separate

346 generalized mixed models (GLMMs), one for each of the response variables. The first model

347 tested whether the preference ratio for the CST differed according to the colony and the second

348 model tested whether the total number of pecks differed between colonies. Both models

349 included the number of experimental sessions that the female needed to reach either of the two

350 learning criteria (i.e. whether she was successful in the $1^{\text {st }}, 2^{\text {nd }}, 3^{\text {rd }}$ or $4^{\text {th }}$ experimental session)

351 as a fixed effect. This variable is later referred to as "sessions to success". Both models included

352 the number (ID) of the set of song stimuli the female was tested with, as a random effect. Due

353 to high collinearity between the variables "female age" and "colony" we could not include

354 female age in the model. Thus, we kept only the variables "colony" and "sessions to success"

355 (there was no collinearity between these two variables). We used error distributions from the

356 quasi family as we detected overdispersion in both models. To test the preference ratio for the

357 CST, we used a GLMM with a quasibinomial distribution and a logit link function. For each

358 female $(\mathrm{N}=37)$, the response variable was weighted by the total number of pecks she made

359 during the four days of test (using the weights parameter). For the total number of pecks, we

360 used a GLMM with a quasipoisson distribution and a log link function. Both models were

361 performed using the glmmPQL function from the MASS package in $\mathrm{R}$. The levels of each

362 explanatory factor (i.e. "colony" and "sessions to success ") were compared to each other by

363 computing post-hoc Tukey tests with the emmeans package in R (Lenth, 2018). 


\section{Results}

41 out of 63 tested females reached one of the two learning criteria. Four females pecked the keys less than 20 times on the second day of test. Those four females were thus excluded from the analysis. Therefore, the results for 37 females were used for further analysis (colony A1: $n=10$; colony A2: $n=11$; colony $B: n=16) .15$ out of these 37 females passed the preference test during the first experimental session (colony A1: $\mathrm{n}=3$; colony $\mathrm{A} 2: \mathrm{n}=5$; colony B: $n=7$ ), three during the second experimental session (colony A2: $n=1$; colony $B: n=2$ ), four during the third experimental session (colony A1: $\mathrm{n}=3$; colony $\mathrm{B}: \mathrm{n}=1$ ), and 15 during the fourth experimental session (colony A1: $n=4$; colony A2: $n=5$; colony B: $n=6$ ) (Table S3). For the number of successful females tested with each set of song stimuli, see Table S2. Among the 37 females kept for analysis, some did not reach the first learning criterion due to their preference for one particular key over the other - i.e. they pecked the non-preferred key less often than 10 times a day (mean number of pecks per day $\pm \mathrm{SD}=1 \pm 2$ ). However, they did reach the second learning criterion. This side preference concerned 17 females: six in colony A1, three in colony A2 and eight in colony B. In the preference analysis of these females, we only focused on pecks on the preferred key and tested whether they pecked more often on the preferred key when it was triggering the CST or when it was triggering the N-CST.

After calculation of each female's preference ratio (number of pecks for the CST/total number of pecks), we witnessed that 26 out of the 37 females significantly preferred one of the two song types, i.e. their preference ratio was significantly different from 0.5 (Figure 3 ). This means they expressed a significant preference for one of the two song types that could be either the CST or the N-CST (colony A1: 7 out of 10, colony A2: 7 out of 11, colony B: 12 out of 16;

386 Figure 3, Table $1 \&$ Table S3). Additionally, among those 26 females out of 37 that showed a preference, 19 preferred the CST over the N-CST (six in colony A1 and A2, seven in colony B; 
Figure 3, Table 1 \& Table S3) and only seven preferred the N-CST over the CST (one in colony A1 and A2, five in colony B; Figure 3, Table $1 \&$ Table S3).

(a)

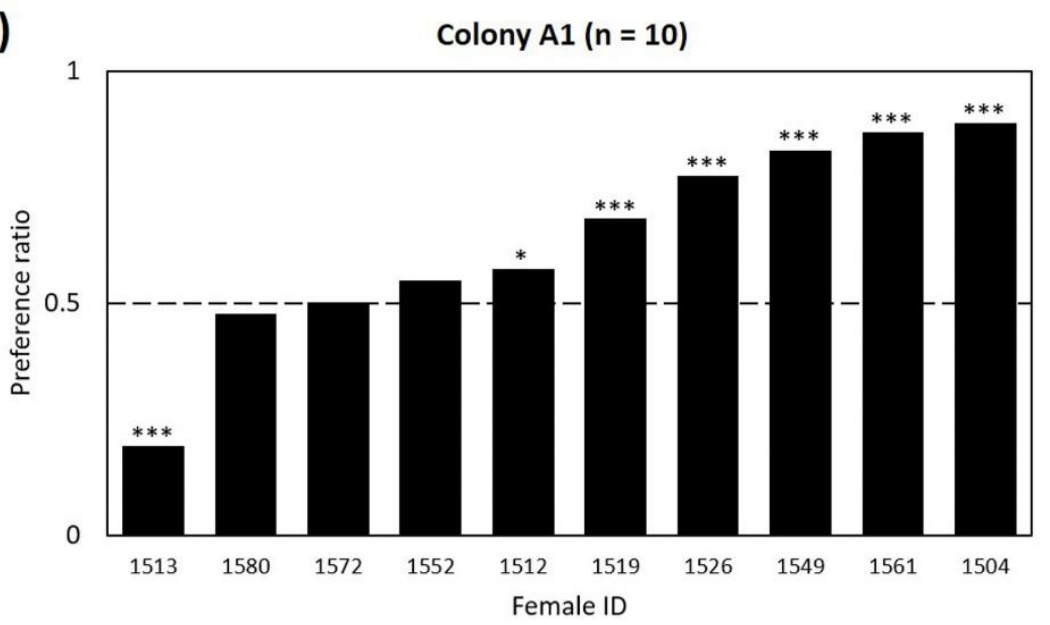

(b)

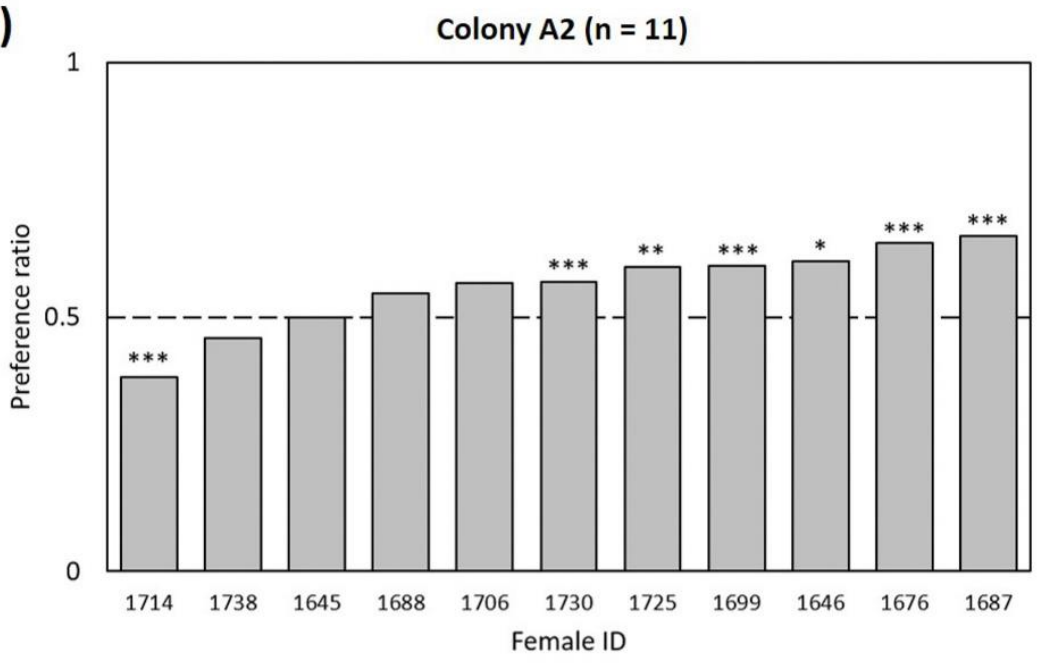

(c)

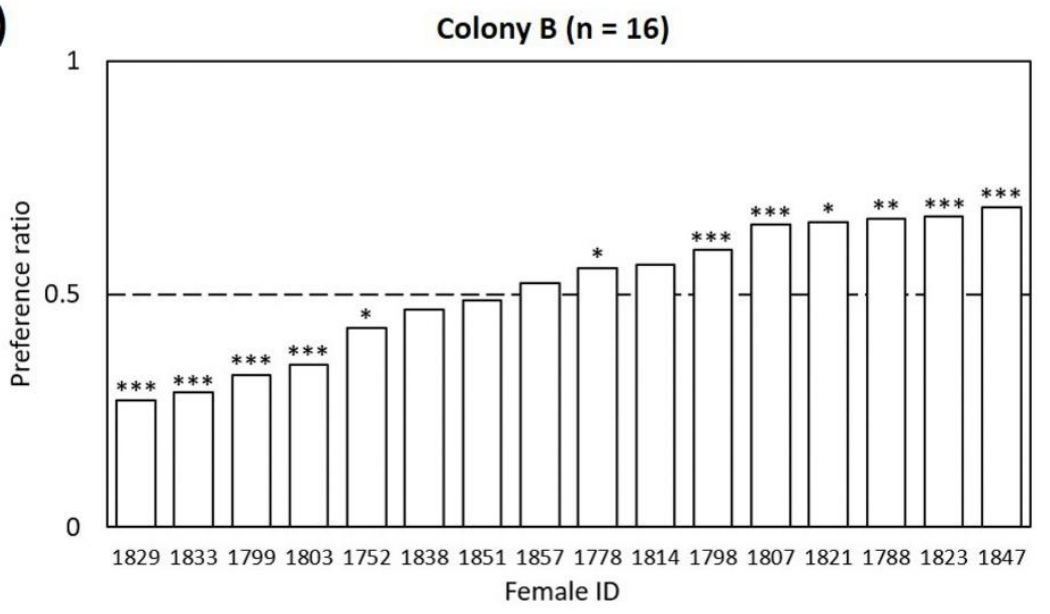

391 Figure 3. Preference ratios (pecks for the Colony Song Type (CST)/total number of pecks) for 392 each female of: (a) colony A1, (b) colony A2, and (c) colony B. Preference ratios approaching 
3931 indicate a preference for the CST, preference ratios approaching 0 indicate a preference for 394 the Non-Colony Song Type (N-CST). Asterisks (*) indicate a significant preference for one of 395 the two song types (see Table 1 and Table S3).

396 Table 1. Number and percentage of tested females in each colony that exhibited no preference, 397 or a significant preference for the Colony Song type (CST) or for the Non-Colony Song Type 398 (N-CST). In each colony, most females showed a preference for the CST.

\begin{tabular}{|c|c|c|c|c|c|c|}
\hline \multirow[b]{2}{*}{ Colony } & \multirow[b]{2}{*}{$\mathrm{n}$} & & \multirow[b]{2}{*}{$\begin{array}{l}\text { Females } \\
\text { without a } \\
\text { preference }\end{array}$} & \multicolumn{3}{|c|}{ Females with a preference } \\
\hline & & & & $\begin{array}{c}\text { For the } \\
\text { CST }\end{array}$ & $\begin{array}{l}\text { For the } \\
\text { N-CST }\end{array}$ & Total \\
\hline \multirow[t]{2}{*}{ A1 } & 10 & $n$ & 3 & 6 & 1 & 7 \\
\hline & & $\%$ & 30 & 60 & 10 & 70 \\
\hline \multirow[t]{2}{*}{$\mathrm{A} 2$} & 11 & $n$ & 4 & 6 & 1 & 7 \\
\hline & & $\%$ & 36 & 55 & 9 & 64 \\
\hline \multirow[t]{2}{*}{$\mathrm{B}$} & 16 & $n$ & 4 & 7 & 5 & 12 \\
\hline & & $\%$ & 25 & 44 & 31 & 75 \\
\hline
\end{tabular}
However, this preference for the colony song type was not reflected at the colony level. 401 The preference for the CST was only significant in colony A2 (tested as a deviation from a 0.5 402 preference ratio with one-sample t-test: $\mathrm{t}=2.30, \mathrm{df}=10, p=0.044$; Figure 4). However, this 403 significant difference disappeared when correcting for multiple testing $\left(p_{\text {adjusted }}=0.126\right)$. In 404 colony A1 and B, the mean preference ratio was not significantly different from chance level 405 of 0.5 (colony A1: $\mathrm{t}=1.94, \mathrm{df}=9, p=0.084, p_{\text {adjusted }}=0.126$; colony $\mathrm{B}: \mathrm{t}=0.31, \mathrm{df}=15, p=$ $406 \quad 0.762, p_{\text {adjusted }}=0.762 ;$ Figure 4$)$. 


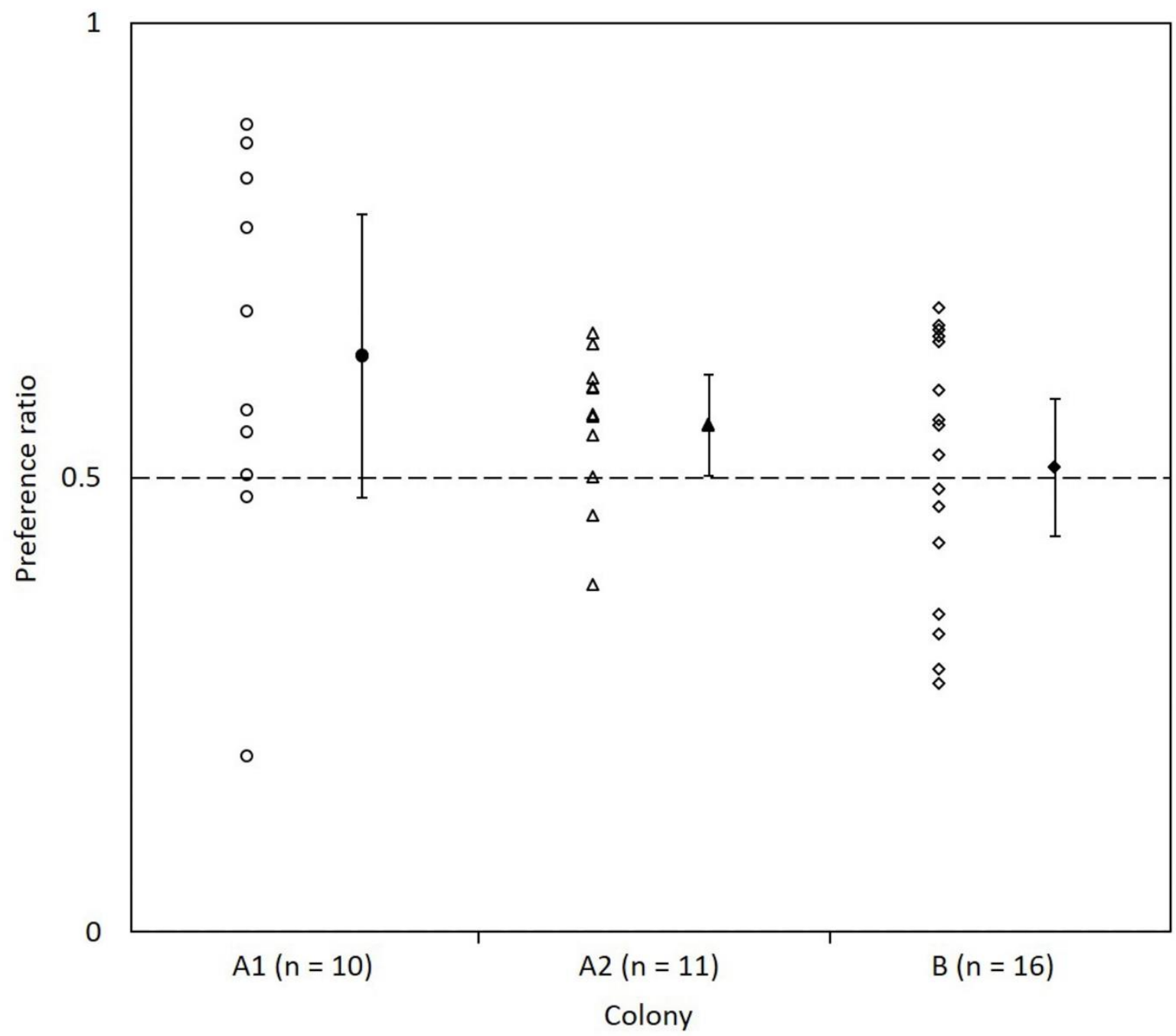

410 Figure 4. Preference ratio for the Colony Song Type (CST) over the Non-Colony Song Type 411 (N-CST) in each colony. Open symbols represent preference ratios of individual females. Filled 412 symbols represent the mean preference ratio (with 95\% confidence interval). Preference ratios 413 approaching 1 indicate a preference for the CST, preference ratios approaching 0 indicate a 414 preference for the N-CST. The mean preference ratio was only significantly different from a 4150.5 preference ratio (dashed line) in colony A2 (one sample t-test, $p=0.044$ ). This significant 416 difference disappeared when correcting for multiple testing $\left(p_{\text {adjusted }}=0.126\right)$. 
419 we tested whether females that pecked more often also had stronger preferences. However, 420 there was no significant correlation between the total number of key pecks and preference 421 strength in any of the colonies (colony A1: $r_{\mathrm{s}}=0.139, p=0.707$; colony A2: $r_{\mathrm{s}}=-0.073, p=$ 4220.839 ; colony B: $\left.r_{\mathrm{s}}=0.444, p=0.087\right)$.

We then further investigated the differences between colonies in the two main responses: preference ratio and total number of key pecks. We found that the preference ratio for the CST was higher in colony A1 than in colony B (Table 2). No difference in the preference ratio was found between the colonies A1 and A2, as well as between colony A2 and colony B

427 (Table 2). As females differed in the number of experimental sessions needed to successfully 428 learn how to peck the keys (Table S3), we also tested whether this factor ("sessions to success") 429 influenced the two main responses. The number of experimental sessions needed to reach either 430 of the two learning criteria did not have any effect on the preference ratio (all pairwise 431 comparisons $n s$, see Table 2). Two colonies differed in their activity levels: we found that 432 females of colony A1 pecked significantly more often on the keys during the test than females 433 of colony B (Table 2). However, there was no significant difference in the total number of pecks 434 between colony A1 and A2 or between A2 and B (Table 2). There was no effect of the number 435 of experimental sessions needed to succeed on the total number of pecks (all pairwise 436 comparisons $n s$, see Table 2). 
437 Table 2. Tukey post-hoc pairwise comparisons for GLMMs on the preference ratio for the 438 Colony Song Type (CST) and on the total number of key pecks during the four days of 439 preference test. Colony and number of experimental sessions needed to reach either of the two 440 learning criteria ("sessions to success") are fixed factors. Significant differences are in bold. df $441=22$.

\begin{tabular}{|c|c|c|c|c|c|c|c|c|c|}
\hline \multirow[b]{2}{*}{$\begin{array}{l}\text { Source of } \\
\text { variation }\end{array}$} & \multirow{2}{*}{$\begin{array}{l}\text { Pairwise } \\
\text { comparison }\end{array}$} & \multicolumn{4}{|c|}{ Preference ratio } & \multicolumn{4}{|c|}{ Total number of key pecks } \\
\hline & & Estimate & SE & $t$ & $p$ & Estimate & SE & $t$ & $p$ \\
\hline \multirow[t]{3}{*}{ Colony } & $\mathrm{A} 1-\mathrm{A} 2$ & 0.462 & 0.301 & 1.534 & 0.295 & 1.032 & 0.518 & 1.993 & 0.138 \\
\hline & A1 - B & 0.657 & 0.239 & 2.753 & 0.03 & 1.423 & 0.528 & 2.693 & 0.034 \\
\hline & $\mathrm{A} 2-\mathrm{B}$ & 0.195 & 0.195 & 0.64 & 0.799 & 0.391 & 0.54 & 0.725 & 0.752 \\
\hline Sessions & $1-2$ & -0.0387 & 0.345 & -0.112 & 0.999 & -1.412 & 0.636 & -2.221 & 0.149 \\
\hline \multirow[t]{5}{*}{ to success } & $1-3$ & -0.4767 & 0.416 & -1.145 & 0.666 & 0.575 & 0.781 & 0.737 & 0.881 \\
\hline & $1-4$ & 0.0229 & 0.232 & 0.099 & 0.99 & -0.244 & 0.462 & -0.527 & 0.951 \\
\hline & $2-3$ & -0.4381 & 0.506 & -0.865 & 0.822 & 1.987 & 0.921 & 2.157 & 0.167 \\
\hline & $2-4$ & 0.0616 & 0.349 & 0.176 & 0.998 & 1.168 & 0.662 & 1.879 & 0.265 \\
\hline & $3-4$ & 0.4996 & 0.403 & 1.239 & 0.61 & -0.819 & 0.747 & -1.097 & 0.695 \\
\hline
\end{tabular}

442

443 Discussion

444 In this study, many female zebra finches (19 out of 37) exhibited a clear preference for 445 the Colony Song Type (CST) over the Non-Colony Song Type (N-CST) whereas few females 446 (seven out of 37) exhibited a preference for the N-CST. Yet, this preference for songs that 447 resembled those produced by males of their colony was not reflected at the colony level. 448 Additionally, these individual preferences were not related to the level of motivation of the 449 females. The preference for the CST as well as the activity levels of females appeared to be 450 stronger in colony A1 than in the colony B, but both were not affected by the number of 451 experimental sessions females needed to reach either of the two learning criteria (10 pecks on 452 each key, or 20 pecks on one of the two keys on a same day). 
Our results are consistent with several previous studies which showed that females of this species prefer the song they experienced during their early life (for a review, see Riebel, 2009). However, the current study differs from those earlier studies that usually gave females a choice between the song of an unfamiliar male and a familiar one, such as the father's song, the tutor's song or a song heard from playback during the sensitive phase of song preference learning (Clayton, 1988; Miller, 1979a; Riebel, 2000; Riebel et al., 2002). The fact that many females still preferred the CST over the N-CST even if it was sung by an unfamiliar individual, suggests that this learned preference was strong enough to be generalised to an unfamiliar songster. This confirms the females' ability to generalise the learnt song preference to songs of unfamiliar males, an ability already demonstrated for zebra finches (Clayton, 1990; Riebel, 2009).

Even if some weak geographical variations in the song had been described in Australian populations of zebra finches (Zann, 1993), the salience of theses variations to females have not been studied so far. Based on artificially created dialects of laboratory colonies, we were able to show here that these acoustic variations matter to female zebra finches. The significance of local song dialects to females for mate choice decisions has been investigated in other species exhibiting geographical song variations naturally. For example, female Nuttall's white-crowned sparrows (Zonotrichia leucophrys nuttalli) were more stimulated by male song of their natal dialect than by male song of adjacent dialects (Baker, 1983). According to the "genetic adaptation hypothesis" we propose that song dialects might matter to female zebra finches in the context of mate choice, as a cue for assortative mating (Tomback \& Baker, 1984). In other words, pairing with a male singing the local song type would ensure the female that her offspring will be genetically adapted to the local environment and will have a better survival and reproductive success than foreign birds (Marler \& Tamura, 1962, 1964; Nottebohm, 1969, 1972; Payne, 1981). Furthermore, it has been argued that female preferences play an important 
role in the stability of song dialects (reviews in Baker \& Cunningham, 1985; Payne, 1981; Rothstein \& Fleischer, 1987). In the brown-headed cowbird (Molothrus ater) females show sexual preferences for the correct local whistle type, which could create a selection pressure on males to conform to the local song type and could influence the stability of dialects (O'Loghlen \& Rothstein, 1995, 2003). The brown-headed cowbird is an interesting case as it is a brood parasitic species in which young birds are not exposed to conspecific song during their early life. Several studies in the zebra finch proposed that male song learning may likewise be influenced by females. For instance, young males imitate a tutor song better when housed with a hearing female than when housed without a female (Adret, 2004) and worse when housed with a deaf female than when housed with a hearing female (Williams, 2004). More recently, another study suggested that the process of song learning in young males could be guided by the social feedback of an adult female zebra finch (Carouso-Peck \& Goldstein, 2019). Given that in the current study females mostly preferred songs of their home dialect, female preferences might have played a role in the establishment and stability of artificial song dialects in our colonies of zebra finches. That is, females' preferences for the CST might have guided young males to conform to this song model.

In most female preference studies on zebra finches, female subjects were sexually naive and housed in single-sex groups with no contact of any sort with males prior to the preference test (e.g. Holveck \& Riebel, 2007; Riebel, 2000; Riebel et al., 2002). In contrast, females in the current study spent their whole lives with males with whom they could interact freely and reproduce during the course of the communal breeding. Their exhibited preferences might therefore have been weaker than if they had been housed separately from males. Mated female zebra finches express a significant preference for their mate's song over an unfamiliar one (Miller, 1979b). Females who did not show a clear preference for the CST in the current study might have been paired to males producing a poor version of this song type. In fact, even if 
most males conformed to the colony's song type, some males produced songs that deviated from it (Derégnaucourt et al., 2014; Le Maguer et al., under review). It is possible that some of our females were paired to males producing such deviant versions of the colony song type, a possibility that we were not able to verify as we did no keep track of their pair bonds.

Despite the individual preferences of females for the CST, this preference was not reflected at the colony level. Moreover, some females exhibited significant preferences for the N-CST. In other species such as canaries (Serinus canaria), females exhibit clear preferences for particular song syllables (Vallet \& Kreutzer, 1995). However, there is no convincing evidence so far that female zebra finches exhibit preferences for particular song features. It rather seems that experience-dependent song preferences of a female zebra finch might interplay with song features of the male's song (such as syllable diversity and spectro-temporal details) to determine which song that female finds attractive (Riebel, 2009). Nevertheless, we cannot exclude that some females in the current study preferred certain N-CST stimuli because of particular sound characteristics.

One could have expected an effect of the number of experimental sessions needed to reach either of the two learning criteria on the preference strength for the CST and the activity level of females. This was not the case, suggesting that the rapidity with which a female learned the operant task was not related to her preference strength or her motivation to peck the keys. However, we did find some differences between the colonies in the preference ratio for the CST and in the activity levels of females during the test. Females of colony A1 exhibited a higher preference ratio for the CST and a higher number of pecks than females of colony B. This is probably not due to the nature of the song dialect (A or B), as females of colony A2 and B did not differ in those variables. It has been reported that experiences of females during adulthood could influence their song preferences (e.g. in canaries, Béguin, Leboucher, \& Kreutzer, 1998; Nagle \& Kreutzer, 1997). In zebra finches, females can develop preferences as adults (Clayton, 
1988; Miller, 1979b; Riebel, 2009). Thus, we could assume that our females' adult experiences with song affected their preference strength. Given that our females were housed with males during their whole lives, we propose that the experience with the song type of males and the ability for females to interact with them reinforced the previously learned preference. When tested, females of colony A1 were much older than females of colony B. Therefore, they had more experience with the CST, which could have resulted in a stronger preference for the CST and a higher motivation to hear it.

In zebra finches, the lack of seasonality in breeding (Immelmann, 1968; Zann, 1996) raises some issues concerning the nature of the observed preferences in females. In our study we did not test for female sexual receptivity. Therefore, we wonder whether females that showed a preference for the CST expressed a sexual preference related to mate choice, or a social preference. In social species, shared song types favour group cohesion (Hausberger et al., 2008). Accordingly, song could be interpreted as an affiliative signal rather than a mere sexual signal in such species. Such social preferences could have played a role in our study as well. To assess this possibility, a social learning task could be used in the future. In zebra finches, the classical observer-demonstrator paradigm has been proven effective to assess social learning in a context of food choice (Benskin, Mann, Lachlan, \& Slater, 2002; Guillette \& Healy, 2014; Katz \& Lachlan, 2003; Riebel, Spierings, Holveck, \& Verhulst, 2012). Therefore, if song dialects do constitute a social marker, an observer might preferentially learn his food choice from a bird singing the CST than from a bird singing the N-CST. Female as well as male zebra finches could be tested as observers to determine whether song dialects could constitute an affiliative signal in this species.

In conclusion, our work expands on numerous studies showing that zebra finch females express a preference for the song they heard early in life but is the first to demonstrate a direct link between song dialects and female preference in this species. Our findings also underline 
553 the difficulty of concluding on whether expressed female preferences in zebra finches are more

554 related to a social or to a sexual preference, but they pave the way to investigate whether song 555 dialects can be used as an affiliative signal in the context of social learning in this model species.

\section{Acknowledgements}

This work was supported by a grant from the French National Agency of Research (ANR-12-BSH2-0009) and the Institut Universitaire de France. LLM was supported by a PhD grant from the University Paris Nanterre. We thank Philippe Groué, Emmanuelle Martin and Ophélie Bouillet for taking care of the birds, Katarina Riebel for her valuable advices on the experimental design and creation of stimuli and Maxime Pineaux for help with statistics.

\section{References}

Adret, P. (2004). Vocal imitation in blindfolded zebra finches (Taeniopygia guttata) is facilitated in the presence of a non-singing conspecific female. Journal of Ethology, 22(1), 29-35. doi: 10.1007/s10164-003-0094-y

Baker, M. C. (1983). The behavioral response of female Nuttall's White-crowned Sparrows to male song of natal and alien dialects. Behavioral Ecology and Sociobiology, 12(4), 309-315. doi: 10.1007/BF00302898

Baker, Myron Charles, \& Cunningham, M. A. (1985). The Biology of Bird-Song Dialects. Behavioral and Brain Sciences, 8(1), 85-100. doi: 10.1017/S0140525X00019750

Beecher, M. D., Campbell, S. E., \& Nordby, J. C. (2000). Territory tenure in song sparrows is related to song sharing with neighbours, but not to repertoire size. Animal Behaviour, 59(1), 29-37. doi: 10.1006/anbe.1999.1304

Béguin, N., Leboucher, G., \& Kreutzer, M. L. (1998). Sexual Preferences for Mate Song in Female Canaries (Serinus Canaria). Behaviour, 135(8), 1185-1196. doi: $10.1163 / 156853998792913500$ 
Benjamini, Y., \& Hochberg, Y. (1995). Controlling the False Discovery Rate : A Practical and Powerful Approach to Multiple Testing. Journal of the Royal Statistical Society: Series B (Methodological), 57(1), 289-300. doi: 10.1111/j.2517-6161.1995.tb02031.x

Benskin, C. M. H., Mann, N. I., Lachlan, R. F., \& Slater, P. J. B. (2002). Social learning directs feeding preferences in the zebra finch, Taeniopygia guttata. Animal Behaviour, 64(5), 823-828. doi: 10.1006/anbe.2002.2005

Briefer, E., Aubin, T., Lehongre, K., \& Rybak, F. (2008). How to identify dear enemies : The group signature in the complex song of the skylark Alauda arvensis. Journal of Experimental Biology, 211(3), 317-326. doi: 10.1242/jeb.013359

Candolin, U. (2003). The use of multiple cues in mate choice. Biological Reviews, 78(4), $575-595$.

Carouso-Peck, S., \& Goldstein, M. H. (2019). Female Social Feedback Reveals Non-imitative Mechanisms of Vocal Learning in Zebra Finches. Current Biology, (29), 631-636. doi: 10.1016/j.cub.2018.12.026

Catchpole, C. K., \& Slater, P. J. B. (2008). Bird Song: Biological Themes and Variations. Cambridge University, Cambridge.

Clayton, N. S. (1988). Song discrimination learning in zebra finches. Animal Behaviour, 36(4), 1016-1024. doi: 10.1016/S0003-3472(88)80061-7

Clayton, N. S. (1990). Subspecies recognition and song learning in zebra finches. Animal Behaviour, 40(6), 1009-1017. doi: 10.1016/S0003-3472(05)80169-1

Cynx, J., \& Nottebohm, F. (1992). Role of gender, season, and familiarity in discrimination of conspecific song by zebra finches (Taeniopygia guttata). Proceedings of the National Academy of Sciences, 89(4), 1368-1371. 
600 Derégnaucourt, S. (2011). Birdsong learning in the laboratory, with especial reference to the

601

602

603

604

605

606

607

608

609

610

611

612

613

614

615

616

617

618

619

620

621

622

623

624 song of the Zebra Finch (Taeniopygia guttata). Interaction Studies, 12(2), 324-350. doi: 10.1075/is.12.2.07der

Derégnaucourt, S., \& Gahr, M. (2013). Horizontal transmission of the father's song in the zebra finch (Taeniopygia guttata). Biology Letters, 9(4), 20130247. doi: $10.1098 / \mathrm{rsbl} .2013 .0247$

Derégnaucourt, S., Nagle, L., Gahr, M., Aubin, T., \& Geberzahn, N. (2014). Cultural Evolution of Birdsong in the Laboratory. Neuroscience annual meeting 2014.

Derryberry, E. P. (2007). Evolution of Bird Song Affects Signal Efficacy: An Experimental Test Using Historical and Current Signals. Evolution, 61(8), 1938-1945. doi: 10.1111/j.1558-5646.2007.00154.x

Edwards, S. V., Kingan, S. B., Calkins, J. D., Balakrishnan, C. N., Jennings, W. B., Swanson, W. J., \& Sorenson, M. D. (2005). Speciation in birds : Genes, geography, and sexual selection. Proceedings of the National Academy of Sciences, 102(suppl 1), 6550-6557. doi: 10.1073/pnas.0501846102

García, N. C., Arrieta, R. S., Kopuchian, C., \& Tubaro, P. L. (2015). Stability and change through time in the dialects of a Neotropical songbird, the Rufous-collared Sparrow. Emu, 115(4), 309-316.

Guillette, L. M., \& Healy, S. D. (2014). Mechanisms of copying behaviour in zebra finches. Behavioural Processes, 108, 177-182. doi: 10.1016/j.beproc.2014.10.011

Harbison, H., Nelson, D. A., \& Hahn, T. P. (1999). Long-Term Persistence of Song Dialects in the Mountain White-Crowned Sparrow. The Condor, 101(1), 133-148. doi: $10.2307 / 1370454$

Hausberger, M., Bigot, E., \& Clergeau, P. (2008). Dialect use in large assemblies : A study in European starling Sturnus vulgaris roosts. Journal of Avian Biology, 39(6), 672-682. 
Holveck, M. J., \& Riebel, K. (2007). Preferred songs predict preferred males : Consistency and repeatability of zebra finch females across three test contexts. Animal Behaviour, 74(2), 297-309.

Houx, A. B., \& ten Cate, C. (1999). Song learning from playback in zebra finches : Is there an effect of operant contingency? Animal Behaviour, 57(4), 837-845. doi: 10.1006/anbe.1998.1046

Immelmann, K. (1969). Song development in the zebra finch and other estrildid finches. Bird vocalizations, 61 .

Immelmann, Klaus. (1968). Zur biologischen Bedeutung des Estrildidengesanges. Journal für Ornithologie, 109(3), 284-299. doi: 10.1007/BF01678374

Jennions, M. D., \& Petrie, M. (1997). Variation in mate choice and mating preferences : A review of causes and consequences. Biological Reviews, 72(2), 283-327.

Katz, M., \& Lachlan, R. F. (2003). Social learning of food types in zebra finches (Taenopygia guttata) is directed by demonstrator sex and feeding activity. Animal Cognition, 6(1), 11-16. doi: 10.1007/s10071-003-0158-y

King, A. P., West, M. J., \& Eastzer, D. H. (1980). Song structure and song development as potential contributors to reproductive isolation in cowbirds (Molothrus ater). Journal of Comparative and Physiological Psychology, 94(6), 1028-1039. doi: 10.1037/h0077737

Kroodsma, D. E. (2004). The diversity and plasticity of birdsong. Nature's music: the science of birdsong, 108-131.

Lachlan, R. F., van Heijningen, C. A., ter Haar, S. M., \& ten Cate, C. (2016). Zebra Finch Song Phonology and Syntactical Structure across Populations and Continents-A Computational Comparison. Frontiers in Psychology, 7. Consulté à l'adresse http://www.ncbi.nlm.nih.gov/pmc/articles/PMC4935685/ 
649 Lauay, C., Gerlach, N. M., Adkins-Regan, E., \& DeVoogd, T. J. (2004). Female zebra finches require early song exposure to prefer high-quality song as adults. Animal Behaviour, 68(6), 1249-1255. doi: 10.1016/j.anbehav.2003.12.025

652 Lenth, R. V. (2018). Estimated Marginal Means, aka Least Squares Means. R Package version 653 1.1.

654

655

656

657

658

659

660

661

662

663

664

665

666

667

668

669

670

671

672

MacDougall-Shackleton, E. A., \& MacDougall-Shackleton, S. A. (2001). Cultural and Genetic Evolution in Mountain White-Crowned Sparrows : Song Dialects Are Associated with Population Structure. Evolution, 55(12), 2568-2575. doi: 10.1111/j.00143820.2001.tb00769.x

MacDougall-Shackleton, S. A., MacDougall-Shackleton, E. A., \& Hahn, T. P. (2001). Physiological and behavioural responses of female mountain white-crowned sparrows to natal-and foreign-dialect songs. canadian Journal of Zoology, 79(2), 325-333.

Marler, P., \& Tamura, M. (1962). Song « Dialects » in Three Populations of White-Crowned Sparrows. The Condor, 64(5), 368-377. doi: 10.2307/1365545

Marler, P., \& Tamura, M. (1964). Culturally transmitted patterns of vocal behavior in sparrows. Science, 146(3650), 1483-1486.

Miller, A. H. (1956). Ecologic Factors that Accelerate Formation of Races and Species of Terrestrial Vertebrates. Evolution, 10(3), 262-277. JSTOR. doi: 10.2307/2406011

Miller, D. B. (1979a). Long-term recognition of father's song by female zebra finches. Nature, $280,389-391$.

Miller, D. B. (1979b). The acoustic basis of mate recognition by female zebra finches (Taeniopygia guttata). Animal Behaviour, 27, 376-380.

Nagle, L., \& Kreutzer, M. L. (1997). Adult female domesticated canaries can modify their song preferences. Canadian Journal of Zoology, 75(8), 1346-1350. doi: 10.1139/z97-759 
673 Nottebohm, F. (1969). The song of the chingolo, Zonotrichia capensis, in Argentina: Description and evaluation of a system of dialects. The Condor, 71(3), 299-315.

675 Nottebohm, F. (1972). The Origins of Vocal Learning. The American Naturalist, 106(947), 116-140. doi: $10.1086 / 282756$

Odom, K. J., Hall, M. L., Riebel, K., Omland, K. E., \& Langmore, N. E. (2014). Female song is widespread and ancestral in songbirds. Nature Communications, 5(1), 1-6. doi: 10.1038/ncomms4379

O’Loghlen, A. L., \& Rothstein, S. I. (1995). Culturally correct song dialects are correlated with male age and female song preferences in wild populations of brown-headed cowbirds. Behavioral Ecology and Sociobiology, 36(4), 251-259. doi: 10.1007/BF00165834

O’Loghlen, A. L., \& Rothstein, S. I. (2003). Female preference for the songs of older males and 684 the maintenance of dialects in brown-headed cowbirds (Molothrus ater). Behavioral Ecology and Sociobiology, 53(2), 102-109. doi: 10.1007/s00265-002-0551-6

Payne, R. B. (1981). Population structure and social behaviour: Models for testing the ecological significance of song dialects in birds: In: Alexander RD \& Tinkle DW (eds): Natural selection and social behaviour: Recent Research and New Theory. Chiron

Payne, R. B. (1982). Ecological Consequences of Song Matching: Breeding Success and Intraspecific Song Mimicry in Indigo Buntings. Ecology, 63(2), 401-411. doi: $10.2307 / 1938958$

Payne, R. B. (1983). The social context of song mimicry: Song-matching dialects in indigo buntings (Passerina cyanea). Animal Behaviour, 31(3), 788-805. doi: 10.1016/S00033472(83)80236-X 
696 Podos, J., \& Warren, P. S. (2007). The Evolution of Geographic Variation in Birdsong. In

697

698

699

700

701

702

703

704

705

706

707

708

709

710

711

712

713

714

715

716

717

718 Advances in the Study of Behavior (Vol. 37, p. 403-458). Academic Press. doi: 10.1016/S0065-3454(07)37009-5

Riebel, K. (2000). Early exposure leads to repeatable preferences for male song in female zebra finches. Proceedings of the Royal Society of London. Series B: Biological Sciences, 267(1461), 2553-2558.

Riebel, K. (2003). The "Mute" Sex Revisited: Vocal Production and Perception Learning in Female Songbirds. In Advances in the Study of Behavior (Vol. 33, p. 49-86). Academic Press. doi: 10.1016/S0065-3454(03)33002-5

Riebel, K. (2009). Song and female mate choice in zebra finches: A review. Advances in the Study of Behavior, 40, 197-238.

Riebel, K., \& Slater, P. J. B. (1998). Testing female chaffinch song preferences by operant conditioning. Animal Behaviour, 56(6), 1443-1453.

Riebel, K., \& Smallegange, I. M. (2003). Does Zebra finch (Taeniopygia guttata) preference for the (familiar) father's song generalize to the songs of unfamiliar brothers? Journal of Comparative Psychology, 117(1), 61-66. doi: 10.1037/0735-7036.117.1.61

Riebel, K., Smallegange, I. M., Terpstra, N. J., \& Bolhuis, J. J. (2002). Sexual equality in zebra finch song preference: Evidence for a dissociation between song recognition and production learning. Proceedings of the Royal Society of London. Series B: Biological Sciences, 269(1492), 729-733. doi: 10.1098/rspb.2001.1930

Riebel, K., Spierings, M. J., Holveck, M.-J., \& Verhulst, S. (2012). Phenotypic plasticity of avian social-learning strategies. Animal Behaviour, 84(6), 1533-1539. doi: 10.1016/j.anbehav.2012.09.029 
Rothstein, S. I., \& Fleischer, R. C. (1987). Vocal Dialects and Their Possible Relation to Honest Status Signalling in the Brown-Headed Cowbird. The Condor, 89(1), 1-23. doi: $10.2307 / 1368756$

Salvin, P., Derégnaucourt, S., Leboucher, G., \& Amy, M. (2018). Consistency of female preference for male song in the domestic canary using two measures: Operant conditioning and vocal response. Behavioural Processes, 157, 238-243. doi: 10.1016/j.beproc.2018.10.004

Searcy, W. A., \& Andersson, M. (1986). Sexual selection and the evolution of song. Annual Review of Ecology and Systematics, 17(1), 507-533.

Tchernichovski, O., Lints, T. J., Derégnaucourt, S., Cimenser, A., \& Mitra, P. P. (2004). Studying the Song Development Process : Rationale and Methods. Annals of the New York Academy of Sciences, 1016(1), 348-363. doi: 10.1196/annals.1298.031

Tchernichovski, O., Nottebohm, F., Ho, C. E., Pesaran, B., \& Mitra, P. P. (2000). A procedure for an automated measurement of song similarity. Animal Behaviour, 59(6), 1167-1176. doi: 10.1006/anbe.1999.1416

Tomback, D. F., \& Baker, M. C. (1984). Assortative mating by white-crowned sparrows at song dialect boundaries. Animal Behaviour, 32(2), 465-469. doi: 10.1016/S0003$3472(84) 80282-1$

Trainer, J. M. (1983). Changes in Song Dialect Distributions and Microgeographic Variation in Song of White-Crowned Sparrows (Zonotrichia leucophrys nuttalli). The Auk, 100(3), 568-582. doi: 10.1093/auk/100.3.568

Vallet, E., \& Kreutzer, M. L. (1995). Female canaries are sexually responsive to special song phrases. Animal Behaviour, 49(6), 1603-1610. doi: 10.1016/0003-3472(95)90082-9

Webster, M. M., \& Rutz, C. (2020). How STRANGE are your study animals? Nature, 582(7812), 337-340. doi: 10.1038/d41586-020-01751-5 
744 Widemo, F., \& Saether, S. A. (1999). Beauty is in the eye of the beholder: Causes and 745 consequences of variation in mating preferences. Trends in Ecology \& Evolution, 14(1), $746 \quad 26-31$.

747 Williams, H. (2004). Birdsong and singing behavior. ANNALS-NEW YORK ACADEMY OF 748 SCIENCES, 1-30.

749 Zann, R. A. (1993). Variation in song structure within and among populations of Australian $750 \quad$ zebra finches. The Auk, 716-726.

751 Zann, R. A. (1996). The zebra finch: A synthesis of field and laboratory studies (Vol. 5). Oxford 752 University Press.

753 

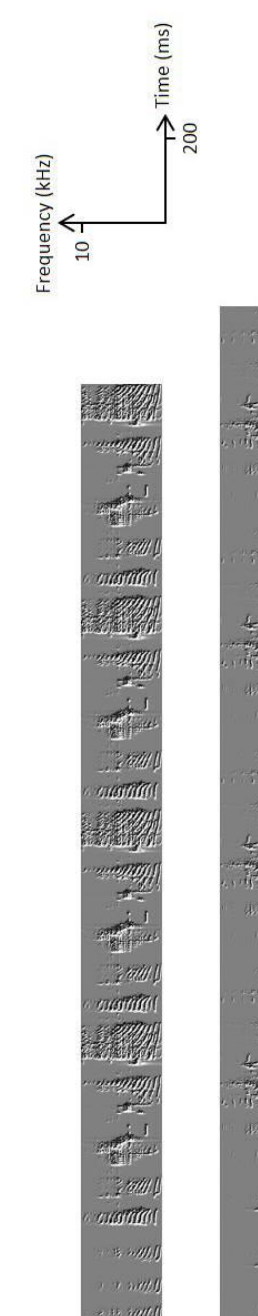
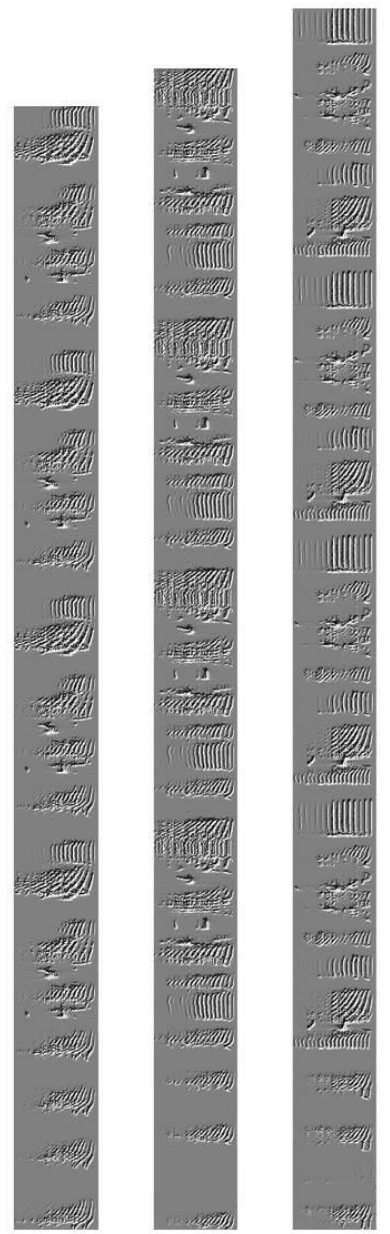

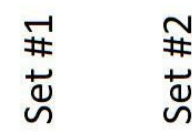

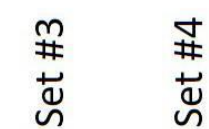

芩 \#
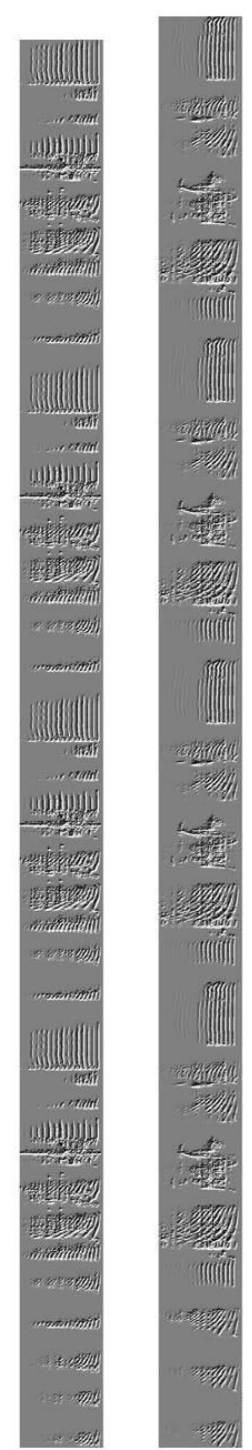

\#

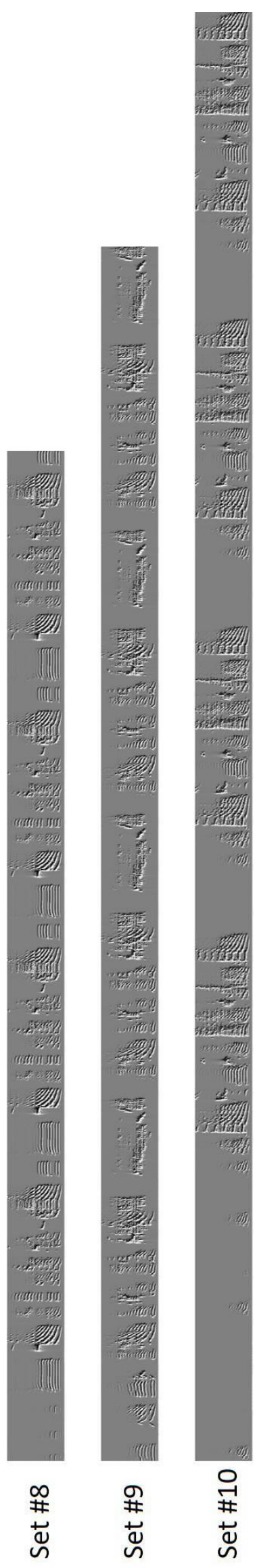


Figure S1. Spectrograms of songs used as a Non-Colony Song Type (N-CST) stimulus.

There was a different N-CST stimulus in each set of song stimuli (a set was composed of one N-CST stimulus and three Colony Song Type (CST) stimuli; one for females of each colony). The 10 N-CST stimuli were recorded from 10 different adult males originating from the Max Planck Institute for Ornithology in Seewiesen (Germany). 
(a)

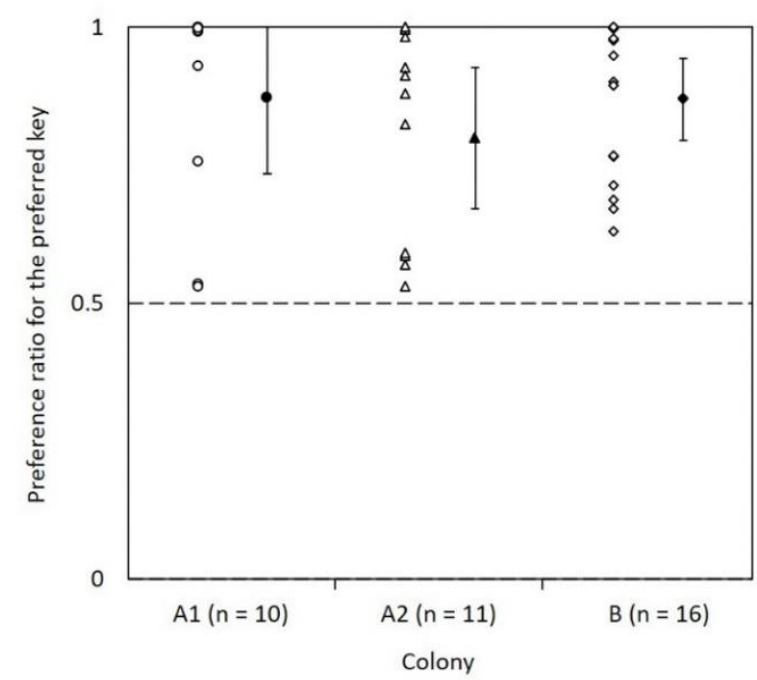

(b)

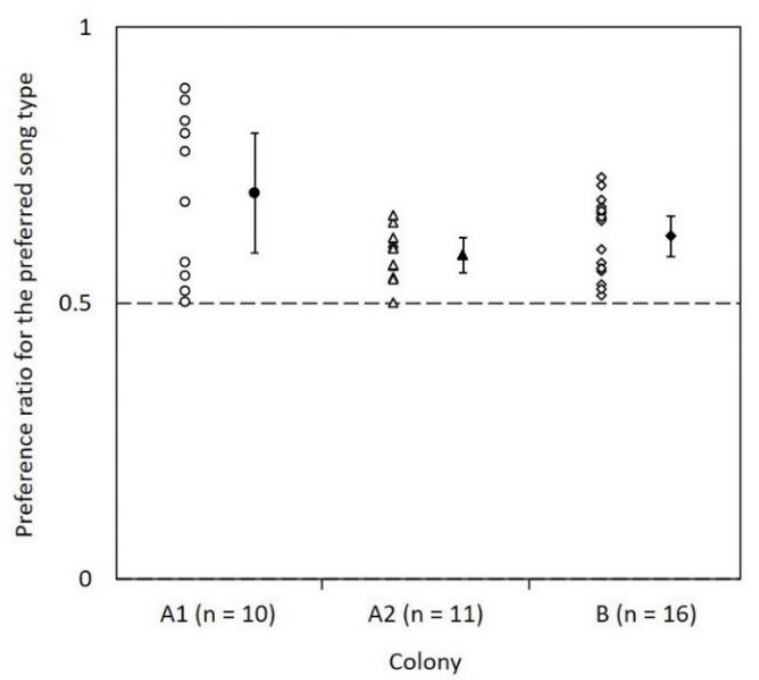

783 Figure S2. Comparison of side preferences and song preferences in each colony. Open

784 symbols represent individual females' preference ratios. Filled symbols represent the mean 785 preference ratio (with 95\% confidence interval). (a) Preference ratio for the preferred key over 786 the non-preferred key. The mean preference ratio was significantly different from a 0.5 787 preference ratio (dashed line) in all colonies (colony $\mathrm{A} 1: \mathrm{t}=6.06, \mathrm{df}=9, \mathrm{p}<0.001, p_{\text {adjusted }}<$ 7880.001 ; colony A2: $\mathrm{t}=5.2, \mathrm{df}=10, \mathrm{p}<0.001$, adjusted $_{\text {a }}<0.001$; colony $\mathrm{B}: \mathrm{t}=10.6, \mathrm{df}=15, \mathrm{p}<$ $7890.001, p_{a d j u s t e d}<0.001$ ). (b) Preference ratio for the preferred song type over the non-preferred 790 song type. The mean preference ratio was significantly different from a 0.5 preference ratio 791 (dashed line) in all colonies (colony A1: $\mathrm{t}=4.16, \mathrm{df}=9, \mathrm{p}=0.0024, p_{\text {adjusted }}=0.0024$; colony 792 A2: $\mathrm{t}=6.09, \mathrm{df}=10, \mathrm{p}<0.001, p_{\text {adjusted }}<0.001$; colony $\mathrm{B}: \mathrm{t}=6.99, \mathrm{df}=15, \mathrm{p}<0.001, p_{\text {adjusted }}$ $793<0.001)$. 
794 Table S1. Duration (s) and singer ID of each song composing the 10 sets of song stimuli.

\begin{tabular}{ccccc}
\hline & \multicolumn{5}{c}{ Song duration (s) } \\
\cline { 2 - 5 } Set & N-CST & $\begin{array}{c}\text { CST for colony } \\
\text { A1 females }\end{array}$ & $\begin{array}{c}\text { CST for colony } \\
\text { A2 females }\end{array}$ & $\begin{array}{c}\text { CST for colony B } \\
\text { females }\end{array}$ \\
\hline 1 & 2.79 & 2.62 & 3.12 & 2.49 \\
2 & 3.03 & 2.82 & 2.98 & 3.19 \\
3 & 3.34 & 2.72 & 2.71 & 3.35 \\
4 & 3.47 & 3.41 & 3.52 & 3.44 \\
5 & 3.64 & 3.37 & 3.46 & 3.53 \\
6 & 4.20 & 2.88 & 3.12 & 3.59 \\
7 & 4.27 & 3.95 & 4.08 & 4.03 \\
8 & 4.45 & 4.34 & 3.94 & - \\
9 & 5.36 & 5.22 & 4.39 & - \\
10 & 6.39 & 5.97 & 6.12 & - \\
\hline & & & Singer ID & CST for colony B \\
Set & N-CST & CST for colony & CST for colony & females \\
\hline 1 & 1 & A1 females & A2 females & 1631 \\
2 & 290 & 1508 & 1741 & 1643 \\
3 & 1103 & 1559 & 1670 & 1593 \\
4 & 13 & 1505 & 1668 & 1720 \\
5 & 466 & 1506 & 1737 & 1722 \\
6 & 325 & 1497 & 1654 & 1680 \\
7 & 406 & 1499 & 1705 & - \\
8 & 559 & 1569 & 1728 & - \\
9 & 1075 & 1547 & 1739 & \\
10 & 63 & 1567 & 1694 & \\
\hline
\end{tabular}

795

796 
Table S2. Number of tested and successful females for each set of song stimuli.

\begin{tabular}{ccccccccc}
\hline & \multicolumn{3}{c}{ Number of tested females } & & \multicolumn{3}{c}{ Number of successful females } \\
\cline { 2 - 4 } \cline { 6 - 8 } Set & Colony A1 & Colony A2 & Colony B & & Colony A1 & Colony A2 & Colony B \\
\hline 1 & 2 & 2 & 4 & & 2 & 1 & 1 \\
2 & 1 & 2 & 4 & & 1 & 1 & 3 \\
3 & 1 & 2 & 5 & & 1 & 2 & 3 \\
4 & 1 & 2 & 5 & & 1 & 1 & 3 \\
5 & 1 & 3 & 5 & & 1 & 2 & 3 \\
6 & 1 & 3 & 4 & & 1 & 0 & 1 \\
7 & 1 & 2 & 4 & & 1 & 1 & 2 \\
8 & 1 & 2 & - & & 1 & 1 & - \\
9 & 1 & 1 & - & & 0 & 1 & - \\
10 & 1 & 2 & - & & 1 & $n$ & - \\
\hline Total & $\mathrm{n}=11$ & $\mathrm{n}=21$ & $\mathrm{n}=31$ & & $\mathrm{n}=10$ & $\mathrm{n}=11$ & $\mathrm{n}=16$ \\
\hline
\end{tabular}

798

799 Note: Tested females: females that entered the testing apparatus. Successful females: females 800 that reached one of the success criteria and completed the entire preference test. 
801 Table S3. Information on the preference test for each tested female of the three colonies.

802 Preference ratios significantly different from 0.5 (chance level) are in bold.

\begin{tabular}{|c|c|c|c|c|c|c|}
\hline Colony & Female ID & $\begin{array}{l}\text { Sessions } \\
\text { to success }\end{array}$ & $\begin{array}{c}\text { Number of pecks } \\
\text { for CST }\end{array}$ & $\begin{array}{c}\text { Total number of } \\
\text { pecks }\end{array}$ & $\begin{array}{c}\text { Preference } \\
\text { ratio }\end{array}$ & $\begin{array}{c}p \text {-value of } \\
\text { binomial test }\end{array}$ \\
\hline \multirow[t]{10}{*}{ A1 } & 1504 & 1 & 776 & 874 & 0.89 & $<0.001$ \\
\hline & 1512 & 3 & 195 & 340 & 0.57 & 0.008 \\
\hline & 1513 & 4 & 56 & 291 & 0.19 & $<0.001$ \\
\hline & 1519 & 1 & 2055 & 3012 & 0.68 & $<0.001$ \\
\hline & 1526 & 4 & 2337 & 3020 & 0.77 & $<0.001$ \\
\hline & 1549 & 3 & 272 & 328 & 0.83 & $<0.001$ \\
\hline & 1552 & 4 & 206 & 375 & 0.55 & 0.063 \\
\hline & 1561 & 3 & 998 & 1150 & 0.87 & $<0.001$ \\
\hline & 1572 & 1 & 127 & 253 & 0.50 & 1 \\
\hline & 1580 & 4 & 976 & 2041 & 0.48 & 0.051 \\
\hline \multirow[t]{11}{*}{$\mathrm{A} 2$} & 1645 & 1 & 62 & 124 & 0.50 & 1 \\
\hline & 1646 & 4 & 101 & 166 & 0.61 & 0.006 \\
\hline & 1676 & 1 & 104 & 161 & 0.65 & $<0.001$ \\
\hline & 1687 & 4 & 108 & 164 & 0.66 & $<0.001$ \\
\hline & 1688 & 4 & 125 & 229 & 0.55 & 0.186 \\
\hline & 1699 & 1 & 495 & 826 & 0.60 & $<0.001$ \\
\hline & 1706 & 4 & 241 & 425 & 0.57 & 0.59 \\
\hline & 1714 & 1 & 144 & 377 & 0.38 & $<0.001$ \\
\hline & 1725 & 1 & 186 & 311 & 0.60 & $<0.001$ \\
\hline & 1730 & 2 & 2030 & 3566 & 0.57 & $<0.001$ \\
\hline & 1738 & 4 & 108 & 236 & 0.46 & 0.216 \\
\hline \multirow[t]{16}{*}{ B } & 1752 & 3 & 153 & 358 & 0.43 & 0.007 \\
\hline & 1778 & 1 & 244 & 438 & 0.56 & 0.019 \\
\hline & 1788 & 4 & 53 & 80 & 0.66 & 0.005 \\
\hline & 1798 & 4 & 1656 & 2779 & 0.60 & $<0.001$ \\
\hline & 1799 & 1 & 142 & 434 & 0.33 & $<0.001$ \\
\hline & 1803 & 1 & 84 & 241 & 0.35 & $<0.001$ \\
\hline & 1807 & 4 & 133 & 205 & 0.65 & $<0.001$ \\
\hline & 1814 & 1 & 72 & 128 & 0.56 & 0.185 \\
\hline & 1821 & 1 & 38 & 58 & 0.66 & 0.025 \\
\hline & 1823 & 4 & 174 & 261 & 0.67 & $<0.001$ \\
\hline & 1829 & 1 & 72 & 264 & 0.27 & $<0.001$ \\
\hline & 1833 & 4 & 147 & 510 & 0.29 & $<0.001$ \\
\hline & 1838 & 2 & 86 & 184 & 0.47 & 0.417 \\
\hline & 1847 & 4 & 153 & 223 & 0.69 & $<0.001$ \\
\hline & 1851 & 1 & 106 & 218 & 0.49 & 0.735 \\
\hline & 1857 & 2 & 186 & 355 & 0.52 & 0.396 \\
\hline
\end{tabular}

